\title{
Validity and reliability of the Myotest Pro wireless accelerometer in squat jumps
}

\author{
Theodoros M. Bampouras ${ }^{\mathrm{a}, *}$, Nicola S. Relph ${ }^{\mathrm{a}}$, Duncan Orme ${ }^{\mathrm{a}}$ and Joseph I. Esformes ${ }^{\mathrm{b}}$ \\ ${ }^{a}$ Sport and Physical Activity, Faculty of Health and Wellbeing, University of Cumbria, Lancaster, UK \\ ${ }^{\mathrm{b}}$ Cardiff Metropolitan University, Cardiff School of Sport, Cardiff, UK
}

Received 6 September 2012

Accepted 20 October 2012

\begin{abstract}
.
BACKGROUND: Portable and cost-effective accelerometers can yield instantaneous results of force, power, and velocity, with minimum set-up time to assess muscle power. However, such devices must also produce both valid and reliable data.

OBJECTIVE: The current study assessed the validity and reliability of the Myotest Pro wireless accelerometer (ACC).

METHODS: Thirty physically active males performed two squat jump, on two separate sessions. The jump was recorded simultaneously by a force platform and ACC, which was attached to a barbell resting on the subjects' shoulders. Validity was determined using Pearson correlation coefficient $(r)$ and t-test between the maximum force platform $\left(\mathrm{F}_{\mathrm{FP}}\right)$ and $\mathrm{ACC}\left(\mathrm{F}_{\mathrm{ACC}}\right)$ force. Between session reliability of $\mathrm{F}_{\mathrm{ACC}}$, power $\left(\mathrm{P}_{\mathrm{ACC}}\right)$ and velocity $\left(\mathrm{V}_{\mathrm{ACC}}\right)$ from the $\mathrm{ACC}$ were assessed with $\mathrm{t}$-test, intraclass correlation coefficient (ICC), and coefficient of variation (CV).

RESULTS: $\mathrm{F}_{\mathrm{ACC}}$ correlated highly to $\mathrm{F}_{\mathrm{FP}}(r=0.815, p<0.05)$, but there was a proportionate ratio bias of 0.81 . There was no difference between sessions $(p>0.05)$ for any variable. High ICCs were found for all variables $\left(\mathrm{F}_{\mathrm{ACC}} 0.90 ; \mathrm{P}_{\mathrm{ACC}} 0.80 ; \mathrm{V}_{\mathrm{ACC}}\right.$ 0.84). Low CV was found for $\mathrm{F}_{\mathrm{ACC}}(2.1 \%), \mathrm{P}_{\mathrm{ACC}}(3.3 \%)$ and $\mathrm{V}_{\mathrm{ACC}}(3.2 \%)$.

CONCLUSIONS: ACC is a valid and reliable tool to use for assessing barbell movement, but caution in power data interpretation is needed.
\end{abstract}

Keywords: Field measurement, muscle performance, power assessment, power production, test-retest design

\section{Introduction}

Muscle power generation is an essential requirement for successful sporting performance [7,13]. Assessing power is important for indicating successful training interventions $[8,9,13]$, offering normative data for monitoring and comparisons [17], and better understanding of the biomechanical mechanisms involved with power generation $[7,9]$.

Technological developments have led to the production of portable and cost-effective accelerometers that

\footnotetext{
*Corresponding author: Theodoros M. Bampouras, Sport and Physical Activity, Faculty of Health and Wellbeing, University of Cumbria, Bowerham Road, Lancaster, LA1 3JD, UK. Tel.: +44 01524526 531; Fax: +44 01524526 527; E-mail: theodoros. bampouras@cumbria.ac.uk.
}

can assess power performance variables real-time or near-real-time in the field $[11,12,20]$. More recently, an accelerometer was developed (Myotest Pro; Myotest SA, Sion, Switzerland) that can yield instantaneous results of force, power, and velocity, with minimum setup time $[5,10]$.

Whilst such devices are more practical for field work assessments, they also need to produce both valid and reliable data. The validity of the Myotest Pro in calculating force and power has been examined in two separate studies $[5,10]$, with reliability only reported in one [5]. However, methodological issues with both studies raise questions as to the accelerometer's ability to assess in a valid and reliable way. Myotest was compared to the Ballistic Measurement System [5], for which to date there is no published study examining its 
validity. Crewther et al. [10] examined the validity of Myotest Pro using twelve healthy individuals. Studies in sport performance research evaluating the validity of measuring methods, require sample sizes sufficiently large to provide an accurate estimate of the measurement error $[1,18]$ and be able to extrapolate the results to the general population [1]. As Crewther et al. [10] discussed in their study, the sample size used was small; a sample of 24-34 subject would be required to detect a moderate effect (for $\alpha=0.05$ and power $=0.8$ ).

Therefore, the aim of the current study was to assess the validity and reliability of the Myotest Pro accelerometer in assessing force against measures obtained using a force platform.

\section{Methods}

\subsection{Subjects}

Thirty physically active males (age $28.3 \pm 8.5 \mathrm{yrs}$, height $1.77 \pm 0.12 \mathrm{~m}$, body mass $79.1 \pm 12.2 \mathrm{~kg}$ ) familiar with the testing procedures and free of any lower limb injuries, volunteered to participate in the study and provided written, informed consent. The study adhered to the declaration of Helsinki and was approved by the University of Cumbria Ethics Committee (ref: 10/02).

\subsection{Procedure}

The subjects visited the laboratory on two separate sessions, seven days apart. On each session, they performed a 5-minute standardised warm-up (5 min of light-intensity cycling and a number of dynamic stretches specific to muscles involved in jumping) followed by 5 minutes rest. Subsequently, the subjects completed two squat jumps with three minutes rest between the jumps. The jumps took place on a calibrated force platform (Bertec, Columbus, $\mathrm{OH}$ ) with an analogue-to-digital converter interfaced to a desktop computer, while data was recorded via Provec v5.0 software (Leeds, UK). The subjects performed the jumps with a lightweight wooden bar (1.2 m length, $0.4 \mathrm{~kg}$ mass) resting on their shoulders and held horizontally, with the accelerometer securely attached on the bar. This set up enabled simultaneous recording of the jump by the force platform and the accelerometer. The baseline weight measurement of the force platform included the system's mass (participant + bar). The system's mass (participant + bar) was entered in the accelerometer before the jump to the closest $0.5 \mathrm{~kg}$. The system measures acceleration on the vertical axis and calculates force by multiplying the mass by the acceleration measured. The accelerometer used was a 3-axis accelerometer (Myotest, Sion, Switzerland), cased in a small rectangular-shaped casing $(5 \times 10 \mathrm{~cm})$ with the whole system weighing $0.06 \mathrm{~kg}$ (www.myotest.com). The system measures acceleration on the vertical axis and calculates force by multiplying the mass by the acceleration measured. It also calculates velocity by integrating acceleration, and subsequently power by multiplying the calculated force and velocity values.

Subjects were instructed to aim for maximum vertical jump height and land on the force platform, while the countermovement depth prior to the jump was selfselected. Care was taken that the accelerometer was maintained at a vertical position throughout the jump and that no rotation of the bar took place, to avoid errors in vertical acceleration. Any jumps that did not fulfil these criteria were disregarded and, following three minutes rest, the participant was asked to repeat the jump. No participant completed more than three jumps on any one session. The jump with the highest force value obtained from the force platform $\left(\mathrm{F}_{\mathrm{FP}}\right)$ and the maximum force $\left(\mathrm{F}_{\mathrm{ACC}}\right)$, power $\left(\mathrm{P}_{\mathrm{ACC}}\right)$, and velocity $\left(\mathrm{V}_{\mathrm{ACC}}\right)$ from the corresponding trial from the accelerometer, were selected from each session for further analysis. Data were collected at a sampling frequency of $500 \mathrm{~Hz}$ for both devices.

The sessions took place at similar times of day and environmental conditions, with the same footwear for each participant. Subjects were instructed to refrain from strenuous exercise 48 hours before testing and consume a similar diet prior to testing sessions.

\subsection{Data processing}

Normality of data was examined and confirmed using the Shapiro-Wilk test. Test-retest score differences and mean scores were correlated to examine for heteroscedasticity [1]. Significant correlation was found for all variables, indicating presence of heteroscedasticity. Hence, the data was transformed using natural logarithm.

A range of statistical tests have been proposed for analysis of repeated trials in reliability studies [1]. We opted for statistical tests that will allow researchers and practitioners to interpret and apply the test they are more familiar with $[1,27]$ and are comparable to previous studies [16,19,26].

Criterion validity was determined from the Pearson correlation coefficient ( $r$ ) and the pairwise difference 
Table 1

Descriptive statistics for Session 1 and $2($ mean \pm SD) and reliability statistics for all variables measured. No significant difference between Session 1 and 2 was found for any variable

\begin{tabular}{lccccc}
\hline & Session 1 & Session 2 & ICC & CV (\%) & SEM \\
\hline $\mathrm{F}_{\mathrm{FP}}$ & $1826.4 \pm 235.2 \mathrm{~N}$ & $1865.4 \pm 255.4 \mathrm{~N}$ & 0.91 & 1.8 & $\times 1 \div 1.00$ \\
$\mathrm{~F}_{\mathrm{ACC}}$ & $2324.3 \pm 451.1 \mathrm{~N}$ & $2308.1 \pm 409.1 \mathrm{~N}$ & 0.90 & 2.1 & $\times 1 \div 1.01$ \\
$\mathrm{P}_{\mathrm{ACC}}$ & $3917.3 \pm 793.2 \mathrm{~W}$ & $4059.4 \pm 943.2 \mathrm{~W}$ & 0.80 & 3.3 & $\times / \div 1.02$ \\
$\mathrm{~V}_{\mathrm{ACC}}$ & $2.68 \pm 0.4\left(\mathrm{~m} \cdot \mathrm{s}^{-1}\right)$ & $2.65 \pm 0.5\left(\mathrm{~m} \cdot \mathrm{s}^{-1}\right)$ & 0.84 & 3.2 & $\times / \div 1.01$ \\
\hline $\mathrm{F}_{\mathrm{FP}}$, force from force platform; & $\mathrm{F}_{\mathrm{ACC}}$, force from accelerometer; $\mathrm{P}_{\mathrm{ACC}}$, power from \\
accelerometer; $\mathrm{V}$ ACC, velocity from accelerometer; ICC, intraclass correlation coefficient; \\
$\mathrm{CV}$, coefficient of variation; SEM, standard error of measurement (presented as ratio).
\end{tabular}

between $\mathrm{F}_{\mathrm{FP}}$ and $\mathrm{F}_{\mathrm{ACC}}$. Reliability within sessions for $\mathrm{F}_{\mathrm{FP}}, \mathrm{F}_{\mathrm{ACC}}, \mathrm{P}_{\mathrm{ACC}}$ and $\mathrm{V}_{\mathrm{ACC}}$ was assessed by a t-test to examine difference within trials, the intraclass correlation coefficient $\left(\mathrm{ICC}_{3,1}\right)$ [25] and coefficient of variation $(\mathrm{CV}$; calculated as standard deviation/mean $\times 100$ for each pair of data and averaged for the sample) [23]. In addition, standard error of measurement (SEM; calculated as the square root of the mean square error term in a repeated measures ANOVA) [1,27] was calculated for $\mathrm{F}_{\mathrm{FP}}, \mathrm{F}_{\mathrm{ACC}}, \mathrm{P}_{\mathrm{ACC}}$ and $\mathrm{V}_{\mathrm{ACC}}$. SEM was anti-log transformd and reported as ratio. Significance level was set at $p \leqslant 0.05$. All statistical tests were performed using SPSSv16.0.

\section{Results}

Mean values from all variables from the two sessions as well as reliability statistics, can be seen in Table 1 .

As there were no test-retest differences within sessions for $\mathrm{F}_{\mathrm{FP}}(p=0.155)$ and $\mathrm{F}_{\mathrm{ACC}}(p=0.4945)$, the values for Session 1 and 2 were averaged to a single participant value [26] for between $\mathrm{F}_{\mathrm{FP}}(\mathrm{N})$ and $\mathrm{F}_{\mathrm{ACC}}$ (N) comparisons. Any bias between the variables remains unaffected by this procedure. $\mathrm{F}_{\mathrm{ACC}}$ demonstrated significant and high correlation to $\mathrm{F}_{\mathrm{FP}}(p=0.001$, $r=0.815$ ), but produced a significant proportionate difference of $0.81(p=0.001)$.

There was also no significant difference between trials for $\mathrm{P}_{\mathrm{PACC}}(p=0.468)$ and $\mathrm{V}_{\mathrm{PACC}}(p=0.464)$. Test-retest repeatability for all variables was high, indicated by a high ICC (range: 0.80-0.91) and a low CV (range: $1.8 \%-3.3 \%$ ). SEM and all reliability statistics for all variables can be seen in Table 1 .

\section{Discussion}

The aim of the current study was to examine the validity and reliability of the Myotest Pro wireless accelerometer during performance of squat jumps, and examine the reliability of all variables obtained (force, power, and velocity). Our results indicate that the accelerometer is a valid and reliable method to assess force, but it can not be used interchangeably with the force platform.

The ability to measure muscular function in the field with relevant measures is important, as it allows for monitoring and evaluation of performance during training not usually afforded with the use of force platforms. However, this should not detract from the fact it must demonstrate adequate validity. The significant correlation of 0.85 between the force platform and the wireless accelerometer is high [4] and indicates sufficient validity of the accelerometer [1].

There was a significant bias between the maximum force obtained from the two devices. The difference can be explained by the way the accelerometer calculates force, using mass and acceleration measured at the point of attachment. The acceleration of the barbell is not the same as the system's acceleration, as the lifter's body does not always move synchronously with the barbell [7]. Inevitably, the accelerometer will record the acceleration of that point plus any additional linear acceleration of the centre of the system's mass $[13,16]$, resulting in overestimation of the force produced.

This limitation is also demonstrated by the use of linear position transducers. Maximum force from a linear position transducer was significantly higher in a similar experimental set-up (countermovement jump, barbell on shoulders, position transducer attached to the barbell) compared to maximum forces obtained from force platform measurements [16]. In contrast, when the linear position transducer was attached to a waist harness (therefore, closer resembling the displacement and acceleration of the centre of mass), maximum force was not significantly different to that measured by the force platform [11]. Similarly, vertical acceleration measured by an accelerometer attached to a barbell and video analysis of the barbell acceleration yielded high agreement, as the measurement was at the same point [24]. 
It is also of importance to note that maximum forces may be developed at different points in the movement, which may contribute to the above difference. Maximum force recorded by the force platform occurs at the bottom of the countermovement and just prior to the centre of mass moving upwards [21]. Contrary, the proximodistal sequence followed by the body's segments for the jump [2], means that maximum acceleration at the distal point of the barbell, where the accelerometer is placed, plus the linear acceleration of the overall system, is achieved after maximum force is achieved.

Notwithstanding the above issues, the selection of the criterion measure and the attachment of the accelerometer were made on practical application grounds. It is common to assess lifting performance in exercises where the barbell and the athlete move independently, e.g. Olympic lifts. In these situations, the point of interest in power generation is the barbell, where the accelerometer should be attached. On the other hand, if the athlete's power output capability is the point of interest, the lifter's body mass must be taken into account, resulting in a combined system (athlete + barbell) mass. Hence, it was of importance not only to assess the validity and reliability of the accelerometer, but to do it in a way that can be applied to different assessment methods and movements.

ICC for $\mathrm{F}_{\mathrm{FP}}, \mathrm{F}_{\mathrm{ACC}}, \mathrm{P}_{\mathrm{ACC}}$ and $\mathrm{V}_{\mathrm{ACC}}$ were high, indicating good test-retest reliability (Table 1). ICC has been widely used and suggested for reliability studies $[1,25]$. Nonetheless, description of which model of ICC was used must be provided [1] as different models can produce different results $[1,25]$. Although interpretation of ICC can be challenging, due to various ICC thresholds published, Fleiss [14] suggested an ICC > 0.75 as 'excellent', while Nunnally and Bernstein [22] highlighted that an ICC $>0.8$ results from small measurement error. ICCs for $\mathrm{F}_{\mathrm{FP}}, \mathrm{F}_{\mathrm{ACC}}$ and $\mathrm{V}_{\mathrm{ACC}}$ ranged from $0.80-0.91$, indicating high reliability between trials. The ICC for $\mathrm{F}_{\mathrm{FP}}$ is similar to the one reported by Cronin et al. [11] who examined validity of a linear position transducer, while the $\mathrm{CV}$ in the present study is slightly lower. It is also important to note that the ICCs between $\mathrm{F}_{\mathrm{FP}}$ and $\mathrm{F}_{\mathrm{ACC}}$ in our study were the same, a similar finding to Cronin et al. [11].

Notwithstanding the widespread use of $\mathrm{CV}$ in the literature, there is no agreed value that indicates reliable equipment [1]. Indeed, the CV has been found to vary between protocols and tests (e.g. sprinting or isokinetic ergometry) [18]. Although a value of $10 \%$ has been used as the threshold for consistency [16], there is little justification for it and the problems in CV as the only measure of reliability have been established [7]. The $\mathrm{CV}$ for $\mathrm{F}_{\mathrm{FP}}$ was similar to other studies (e.g. 2.8\%, $2 \%$ ) $[6,11]$, while the $\mathrm{CV}$ for $\mathrm{F}_{\mathrm{ACC}}$ was similar to a linear position transducer $(2.9 \%)$ [11]. Finally, $\mathrm{V}_{\mathrm{ACC}}$ produced a low $\mathrm{CV}$, indicating sufficient reliability.

$\mathrm{P}_{\mathrm{ACC}}$ yielded slightly lower ICC than $\mathrm{F}_{\mathrm{FP}}$ and $\mathrm{F}_{\mathrm{ACC}}$ and a slightly higher CV. Reliable power tests produce generally low CV values (range: $2 \%-<4 \%$ ) [18], which compares favourably with the current study. In contrast, when assessing the reliability of an accelerometer against kinematics analysis, Thompson and Bemben [26] reported a CV of $20 \%$, which is much higher than the $\mathrm{CV}$ in our study. The higher power $\mathrm{CV}$ values obtained from accelerometers can be explained by the calculation method. Once acceleration is measured, the data needs to be manipulated to calculate velocity and force. As a result, both variables resulting in the power product are error prone. The error may also be augmented by the inclusion of the body mass as a constant prior to the jump. Although typically the system's mass is included (ie participant + barbell), the shanks and feet contribute very little to the overall mass moved and it has been suggested that exclusion of this mass should take place for accurate results $[9,13]$.

It is of interest to strength and conditioning coaches to be able to evaluate whether changes in measured variables between sessions are true effects (e.g. improvement in strength performance) rather than error in measurement. The use of SEM was suggested to assist with this and can be used to estimate the minimum difference and used in the interpretation of scores in individual athletes. The equation to achieve this is $\mathrm{SEM} \times 1.96 \times$ SQRT(2) [3], which provides the minimum difference that represents a true change; any value outside that minimum difference indicates true increase or decrease in the measured variable (with $95 \%$ confidence).

In conclusion, portable equipment that can assess muscle force generation and related parameters has great value in the design of an athletic training programme as well as monitoring the athletes' improvements. However, any tool must be both valid and reliable. Myotest Pro can offer great portability and ease in assessing the athlete and the findings of the current study indicated that Myotest Pro is a valid and reliable tool to assess squat jump performance and it can provide the coach with important information on performance changes. 


\section{References}

[1] Atkinson G, Nevill AM. Statistical methods for assessing measurement error (reliability) in variables relevant to sports medicine. Sports Med. 1998; 26(4): 217-238.

[2] Bobbert MF, van Soest AJ. Why do people jump the way they do? Exerc Sport Sci Rev. 2001; 29(3): 95-102.

[3] Charter RA. Revisiting the standard errors of measurement, estimate and prediction and their application to test scores. Percept Mot Skills. 1996; 82(3): 1139-1144.

[4] Cohen J. Statistical power analysis for the behavioral sciences. 2nd ed. Mahwah, NJ: Lawrence Erlbaum; 1988.

[5] Comstock BA, Solomon-Hill G, Flanagan SD, Earp JE, Luk HY, Dobbins KA, et al. Validity of the Myotest ${ }^{\circledR}$ in measuring force and power production in the squat and bench press. $\mathrm{J}$ Strength Cond Res. 2011; 25(8): 2293-2297.

[6] Cormack SJ, Newton RU, McGuigan MR, Doyle TL. Reliability of measures obtained during single and repeated countermovement jumps. Int J Sports Physiol Perform. 2008; 3(2): 131-144.

[7] Cormie P, McBride JM, McCaulley GO. Power-time, forcetime, and velocity-time curve analysis of the countermovement jump: impact of training. J Strength Cond Res. 2009; 23(1): 177-186.

[8] Cormie P, McBride JM, McCaulley GO. Power-time, forcetime, and velocity-time curve analysis during the jumps squat: impact of load. J Appl Biomech. 2008; 24(2): 112-120.

[9] Cormie P, McBride JM, McCaulley GO. Validation of power measurement techniques in dynamic lower body resistance exercises. J Appl Biomech. 2007; 23(2): 103-118.

[10] Crewther BT, Kilduff LP, Cunningham DJ, Cook C, Owen $\mathrm{N}$, Yang GZ. Validating two systems for estimating force and power. Int J Sports Med. 2011; 32(4): 254-258.

[11] Cronin JB, Hing RD, McNair PJ. Reliability and validity of a linear position transducer for measuring jump performance. $\mathrm{J}$ Strength Cond Res. 2004; 18(3): 590-593.

[12] Drinkwater EJ, Galna B, McKenna MJ, Hunt PH, Pyne DB. Validation of an optical encoder during free weight resistance movements and analysis of bench press sticking point power during fatigue. J Strength Cond Res. 2007; 21(2): 510-517.

[13] Dugan EL, Doyle TLA, Humphries B, Hasson CJ, Newton RU. Determining the optimal load for jump squats: a review of methods and calculations. J Strength Cond Res. 2004; 18(3): 668-674.
[14] Fleiss JL. Design and analysis of clinical experiments. New York, NY: John Wiley \& Sons; 1986.

[15] Glatthorn JF, Gouge S, Nussbaumer S, Stauffacher S, Impellizzeri FM, Maffiuletti NA. Validity and reliability of Optojump photoelectric cells for estimating vertical jump height. J Strength Cond Res. 2011; 25(2): 556-560.

[16] Hansen KT, Cronin JB, Newton MJ. The reliability of linear position transducer and force plate measurement of explosive force-time variables during a loaded jump squat in elite athletes. J Strength Cond Res. 2011; 25(5): 1447-1456.

[17] Hertogh C, Hue O. Jump evaluation of elite volleyball players using two methods: jump power equations and force platform. J Sports Med Phys Fitness. 2002; 42(3): 300-303.

[18] Hopkins WG, Schabort EJ, Hawley JA. Reliability of power in physical performance tests. Sports Med. 2001; 31(3): 211234.

[19] Hori N, Newton RU, Kawamori N, McGuigan MR, Kraemer WJ, Nosaka K. Reliability of performance measurements derived from ground reaction force data during countermovement jump and the influence of sampling frequency. J Strength Cond Res. 2009; 23(3): 874-882.

[20] Jennings CL, Viljoen W, Durandt J, Lambert MI. The reliability of the FitroDyne as a measure of muscle power. J Strength Cond Res. 2005; 19(4): 859-863.

[21] Linthorne NP. Analysis of standing vertical jumps using a force platform. Am J Phys. 2001; 69(11): 1198-1204.

[22] Nunnally J, Bernstein I. Psychometric Theory. 3rd ed., New York, NY: McGraw Hill; 1994.

[23] Sale DG. Testing strength and power. In: MacDougall JD, Wenger HA, Green HJ, editors. Physiological Testing of the High Performance Athlete. 2nd ed., Champaign, IL: Human Kinetics; 1991; pp. 21-106.

[24] Sato K, Smith SL, Sands WA. Validation of an accelerometer for measuring sport performance. J Strength Cond Res. 2009; 23(1): 341-347.

[25] Shrout PE, Fleiss JL. Intraclass correlations: uses in assessing rater reliability. Psychol Bull. 1979; 86(2): 420-428.

[26] Thompson CJ, Bemben MG. Reliability and comparability of the accelerometer as a measure of muscular power. Med Sci Sports Exerc. 1999; 31(6): 897-902.

[27] Weir JP. Quantifying test-retest reliability using the intraclass correlation coefficient and the SEM. J Strength Cond Res. 2005; 19(1): 231-240. 
Copyright of Isokinetics \& Exercise Science is the property of IOS Press and its content may not be copied or emailed to multiple sites or posted to a listserv without the copyright holder's express written permission.

However, users may print, download, or email articles for individual use. 